the clinical facts about each case, so that when in the second the children were given autogenous vaccine or placebo at random the results could be compared with those of the previous year. It was found that children receiving the placebo had $13.8 \%$ days of wheezing compared with $21.7 \%$ the previous year, while the figures for the vaccine group were $21.0 \%$ and $18.5 \%$. The apparent superiority of placebo may have been due to the control group having two-thirds of the children over 9, while in the vaccine-treated group twothirds were less than 9 . Since asthma may improve at puberty the two groups are not strictly comparable. This fact allows criticism of this trial and doubtless another will follow.

Despite the detailed criticism of each trial there is no experimental evidence supporting the use of vaccines in asthma. On the debit side there is evidence that patients become dependent on weekly doses of vaccine. The danger of starting a patient on a course of treatment he may refuse to abandon later should be borne in mind before starting vaccine therapy.

\section{Drug Resistance in Malaria}

In the days when quinine was the sole antimalarial, true drug-fastness to it was unknown. Strains of parasites, it was recognized, did vary slightly in their susceptibility to it, but these variations were of minor degree; no strain became insusceptible to the accepted therapeutic doses of the drug. With the development of the synthetic antimalarials, which have largely supplanted quinine, the situation has changed.

Mepacrine, the first of these compounds to be widely employed, proved therapeutically effective. It was unpopular because of side-effects and even severe toxicity in some cases. But resistance to mepacrine was not encountered, and it was used both for prophylactic and for therapeutic purposes for some years without evidence of its development. When proguanil (Paludrine) came into use it was found to be singularly free from side-effects; indeed, it can be given in doses well above the accepted without toxic manifestations, having a margin of safety which is enjoyed by no other antimalarial. Though too slow in action for most therapeutic purposes, proguanil has nevertheless a valuable role as a prophylactic. Unhappily, early in its use it became clear that resistance to it could be developed by Plasmodium vivax, which causes benign tertian malaria, and by $P$. falciparum, which causes malignant tertian malaria, and that this resistance could become total. To the chemically allied drug pyrimethamine (Daraprim), likewise in extensive use as a prophylactic, resistance can also be developed, and resistance to either proguanil or pyrimethamine is common to both. Strains of parasites in limited areas where malaria is endemic have become resistant to these particular drugs, and there alternative drugs must be used. But this does not mean that these two should universally be abandoned ; they still are the prophylactic antimalarials of choice except in those areas where the parasites are proved to be refractory to them. Furthermore, resistance to both of them does not entail resistance to the other antimalarial drugs in common use.

The other antimalarials of great therapeutic and of prophylactic value are chloroquine and amodiaquine, both

\footnotetext{
1 Macdonald, G., Brit. med. F., 1965, 2, 229.

Wld Hlth Org. techn. Rep. Ser., No. 296, 1965

3 Wilson, T., Lancet, 1965, 2, 747

- Lasch, E. E., and N'Guyen, T. L., Brit. med. 7., 1965, 2, 1219.
}

of them 4-amino-quinolines. For therapeutic purposes they are generally held to equal, and even to surpass, quinine or mepacrine, and they are greatly superior to quinine for prophylaxis. Of the two chloroquine is the more commonly used. But it came as a shock to find, first in South America and later elsewhere in the tropics, that resistance of malaria parasites to chloroquine had developed in some localities. More alarming still, some chloroquine-resistant strains of parasites have proved to be resistant to all the other synthetic antimalarials, though fortunately not to quinine. And so quinine is restored to a place of importance in the treatment of malaria under certain circumstances.

Possibly, as with scme other drugs, irregular treatment or continued ineffectual treatment may cause resistant strains to appear. To-day expert opinion recommends the exclusive use of proguanil or of pyrimethamine for routine prophylaxis against malaria in those areas where resistance to them has not been found-and that means wherever malaria is endemic except for certain recognized areas. Outside these the use of 4-aminoquinolines should be abandoned as prophylactic antimalarials so as to minimize the risk of the development of strains of parasites resistant to them. ${ }^{1}$ They should be reserved for therapeutic purposes only-that is, for the treatment of the acute disease and, in the case of malignant tertian malaria, the eradication of the infection. Alone, they will not sterilize the patient of benign tertian malaria. Consequently in this form of malaria an 8-aminoquinoline drug, such as primaquine, must also be given to eradicate the exoerythrocytic cycle of the parasite, which causes the relapses.

Before a case of malaria is presumed drug-fast to any compound or series of compounds detailed studies are essential..$^{2}{ }^{3}$ As E. E. Lasch and T. L. N'Guyen ${ }^{4}$ have pointed out, statements by patients, though honestly made, are often misleading. An antimalarial drug given by mouth must be absorbed to be of therapeutic value. Chemical tests are necessary to ensure that this in fact has taken place, for many individual cases of alleged resistance to an antimalarial drug have proved on simple clinical investigation to have another cause. But knowledge of a patient's sojourn in a district where the presence of drug-resistance has been proved suggests particularly close observation of the response to treatment of his infection. If this is abnormal, then the laboratory is the place to establish the reason for it.

\section{Mumps of the Heart}

Death from congestive cardiac failure eight months after probable mumps is sufficiently rare to attract attention. Nevertheless, a report by W. C. Roberts and S. M. Fox ${ }^{1}$ leaves no doubt about the correctness of the diagnosis, while necropsy showed hypertrophy of the heart and the histological changes of diffuse interstitial myocardial fibrosis.

${ }^{1}$ Roberts, W. C., and Fox, S. M., Circulation, 1965, 32, 342.

2 Grönberg, A., and Nordin, N. G., T. milit. Hálsov, 1941, 66, 14.

3 Dahl, S., Dtsch. med. Wschr., 1950, 75, 1647.

4 Rosenberg, D. H., Proc. Soc. exp. Biol., 1945, 58, 9.

5 Rosenberg, D. H., Proc. Soc. exp. Biol., 1945, 58, 9.

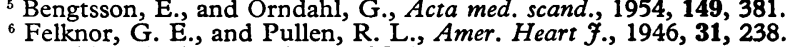

${ }^{6}$ Felknor, G. E., and Pullen, R. L., Amer. Heart $\mathcal{Y}$

\& Manca, C., Arch. Ital. di Anat. e Istol. Patol, 1932, 3, 707.

9 Saphir, O., and Cohen, N. A., Arch. Path., 1957, 64, 446.

10 Cossart, Y. E., Burgess, J. A., and Nash P. D., Med. F. Aust., 1965, 1, 337.

${ }^{11}$ Dunnet, W. N., Brit. med. $\mathcal{F}, 1963,1,1187$.

${ }_{12}$ Krakower, C. A., and Roberg, N. B., Amer. Heart F., 1962, 63, 276. 